\title{
Erratum to: Proteomic Analysis of the Defense Response of Wheat to the Powdery Mildew Fungus, Blumeria graminis f. sp. tritici
}

\author{
Md. Siddikun Nabi Mandal ${ }^{1,2} \cdot{\text { Ying } \mathrm{Fu}^{1}}^{1}$ Sheng $\mathrm{Zhang}^{3} \cdot{\text { Wanquan } \mathrm{Ji}^{1}}^{1}$
}

Published online: 21 May 2015

(C) Springer Science+Business Media New York 2015

\section{Erratum to: Protein J (2014) 33:513-524 DOI 10.1007/s10930-014-9583-9}

After the publication of this work, we were made aware of an error in the order of the affiliations of one of the authors. The correct affiliations are listed with this erratum.
The corrections do not affect any results or conclusions of the published work.

The online version of the original article can be found under doi:10.1007/s10930-014-9583-9.

Wanquan Ji

jiwanquan2003@126.com

Md. Siddikun Nabi Mandal

snabibari@gmail.com

1 State Key Laboratory of Crop Stress Biology for Arid Areas, College of Agronomy, Northwest A\&F University, No. 3

Taicheng Road, Yangling 712100, Shaanxi, China

2 Wheat Research Centre, Bangladesh Agricultural Research Institute, Nashipur, Dinajpur, Bangladesh

3 College of Forestry, Northwest A\&F University, Yangling 712100, Shaanxi, China 